\title{
APPLYING THE STERILE INSECT TECHNIQUE FOR BIOSECURITY: BENEFITS AND CONSTRAINTS
}

\author{
D.M. SUCKLING \\ HortResearch, PO Box 51, Lincoln, New Zealand \\ Corresponding author: msuckling@hortresearch.co.nz.
}

\begin{abstract}
Sterile insect releases to manage or eradicate pests have been deployed increasingly in many countries against diverse targets, but have not previously been seriously considered in New Zealand. The increasing cost of incursions of exotic species warrants a reconsideration of the potential for any approach that can help to defend New Zealand. The success of the sterile insect technique is dependent on adequate understanding of pest biology, techniques for mass rearing of sufficient numbers to overcome the target population, mass sterility (with excellent quality assurance), competitive fitness of released insects, and release systems that ensure effective spatial targeting. Legislative hurdles such as the HSNO Act (1996) may need attention to enable this approach for insects that have arrived after 1998. The first use of the sterile insect technique in New Zealand is against the painted apple moth, and is a useful case study to demonstrate the potential of the approach in biosecurity.
\end{abstract}

Keywords: biosecurity, sterile insect technique, insects.

\section{INTRODUCTION}

Insects comprise a significant proportion of the exotic organisms that threaten New Zealand's biosecurity. New tools and technologies are urgently needed to improve options for post-border biosecurity responses (Goldson \& Suckling 2003). This need for postborder solutions has been made obvious by recent experiences with a wide range of new incursions, including tropical grass webworm, guava moth, painted apple moth, fall webworm, Asian gypsy moth and gum leaf skeletoniser. While the painted apple moth has just become the first ever target of the sterile insect technique (SIT) in New Zealand, many other species and insect orders are potentially vulnerable to the approach. A brief review of the sterile insect technique is warranted, before the potential wider relevance of the approach to biosecurity can be considered.

The sterile insect technique involves mass rearing, sterilising and releasing large numbers of insects to reduce or eliminate subsequent generations of feral populations of the target pest (Knipling 1979). Ideally, sterile insects competitively mate with the target population, and the subsequent reduction in the number of feral progeny is proportional to the number of sterile insects released. Knipling provided an arithmetic analysis of the potential of SIT for population suppression as early as 1937, although the first field trial was not conducted until the mid-1950s (Bartlett \& Staten 2003).

A variation on the original approach is termed "inherited sterility", and involves the release of partially sterile insects of superior fitness. Partially sterile males have been found to be more effective at overall population suppression because of greater fitness of the irradiated fathers and resulting heterozygote offspring, and hence penetration of the transformed dominant lethal genotypes into the wild population. The phenomenon of inherited sterility was first discovered in silk worm in 1935 (Astaurov \& Frolova 1935, cited in Tothová \& Marec 2000) and is now the preferred approach for SIT, as it has been shown to provide much greater population suppression, due to the requirement for competitive mating (LaChance 1985). The survival and mating of released sterile 
$\left(\mathrm{F}_{0}\right)$ insects thus multiplies their effective impact through the increased number of sterile $\mathrm{F}_{1}$ progeny. This temporary increase in the target population is unlikely to be a concern for biosecurity applications, although pest damage can occur in the $\mathrm{F}_{1}$ generation (thereby raising concerns about use of this tactic in pest management).

The technique typically uses radioactive sources $\left(\mathrm{e} . \mathrm{g} . \mathrm{Co}^{60}\right)$ to sterilise, although there are alternative approaches, such as chemical sterilants. More recent approaches using biotechnology have advanced the wider concept (also called "autocidal" control), using the introduction of specific deleterious mutations into the population (Robinson \& Franz 2000). This technology would require the approval of the Environmental Risk Management Authority (operating under the Hazardous Substance and New Organisms Act (1996)) before field release of genetically modified organisms in New Zealand, and is beyond the scope of this paper.

This paper will focus on the most widely developed concept of the sterile insect technique, inherited sterility, and will consider the relevance of this internationally-proven technique to New Zealand biosecurity. Cost-benefit analyses of SIT have been conducted for a number of individual target species (Hendrichs 2002), and have shown competitive returns compared with alternative tactics. However, such analyses need to be considered on a case-by-case basis, and programme cost is not considered in detail here.

\section{RELEVANCE OF SIT TO NEW ZEALAND'S BIOSECURITY}

The SIT is biologically-based and species-specific, unlike most other potential control tactics for use in pest eradications. It increases in effectiveness with decreasing density of the target pest (i.e. is inversely density-dependent), making it more useful in biosecurity applications in the early or final stages of eradication. The technique is compatible with all other tactics, and is likely to be especially effective when combined with other inversely density-dependent tactics, such as mating disruption. Such combinations of SIT and other tactics have been tested for pest management (e.g. Bloem et al. 2001). It is entirely compatible with the general arsenal of tactics, such as ground or aerial spraying of insecticides (including biopesticides like Btk; O'Callaghan \& Glare (2003)) and habitat removal. It is also entirely compatible with mass trapping, and in this context offers a considerable amount of additional relevant biological information on field populations (e.g. dispersal, trap efficiency and population size of the pest). The sterile insect technique offers the additional advantage that the sterile insects seek and mate with cryptic insects at low density. No other incursion response tactic offers this advantage. A further important advantage of SIT over existing tactics is that it does not produce the perceived or real impacts of an aerial spray programme. This is likely to be of greatest advantage in urban environments, where dealing with incursions is especially challenging (Suckling 2000).

\section{TARGET INSECT ORDERS}

Several insect orders have been the target of SIT. Diptera have been the most targeted order, and the best known case involves the New World screwworm, Cochliomyia hominivorax, which was driven out of Mexico down towards Panama using SIT (Hendrichs 2002). Another major target has been the Mediterranean fruit fly Ceratitis capitata (Krafsur 1998). SIT has been used to eradicate this and other fruit fly pests in Chile, Mexico, parts of Patagonia and Australia, and urban areas of USA. Billions of sterile fruit flies are now produced weekly (Hendrichs et al. 2002). Queensland fruit fly Bactrocera tryoni (Meats 1996) has also been eradicated in southern Australia.

There are a number of examples of successful pest suppression or local eradications against Lepidoptera, including pink bollworm (Pectinophora gossypiella), gypsy moth (Lymantria dispar), codling moth (Cydia pomonella), corn earworm (Heliothis zea) and tobacco hornworm (Manduca sexta)(Bartlett \& Slaten 2003).

Eradications of other groups have been achieved, including whitefly (Bemisa tabaci) (Calvitti et al. 1998) and sweet potato weevils (Moriya \& Miyatake 2001), and it seems likely that this list will increase as other countries increasingly realise the potential of SIT in the eradication of exotic pests. 


\section{REQUIREMENTS FOR A SUCCESSFUL SIT PROGRAMME}

Knowledge of the pest's biology is the key to the success of this tactic, as with any biologically-based response to pests. Information is needed on migration and mating behaviour, host range, radiation biology and the availability of monitoring tools (IAEA 2000). The best targets have low mobility, mate once, are univoltine, and have a narrow host range.

In addition, operational factors need to be considered. Success of SIT depends on a number of important assumptions being met (Table 1). The cost of the tactic is strongly influenced by the need for mass-rearing, which may not be feasible for all potential targets. Mass rearing systems have been developed for a wide range of species, but the development of rearing systems for new species takes time and expertise, and the challenge of mass rearing high quality insects cannot be lightly dismissed. Quality assurance needs to focus on fitness for purpose, which here overlaps with the evolutionary concept of fitness due to the need for competitive mating by the released insects.

It is far easier to monitor progress with SIT where trapping systems (e.g. pheromones or kairomones) are available. This may have contributed to the greater targeting of the SIT approach to Diptera and Lepidoptera, along with other attributes of ideal target pest biology indicated in Table 1. Evaluation systems (e.g. trapping) must cover the entire population being targeted.

It is absolutely critical to maintain an effective ratio of sterile to feral insects in time and space. Release systems must ensure effective targeting spatially and temporally, and recognise spatial aggregation or phenological events. It is essential to have information on the competitive fitness of released insects, effectively maximising mating with the target population. This can include detection of chromosomal abnormalities in the offspring of irradiated males (Carpenter 1991; Tothová \& Marec 2000). Systems for detecting damaged chromosomes in pheromone trapped male moths are not yet developed (J. Carpenter, pers. comm.), although this would be highly desirable as a routine system for assessing SIT effectiveness through measuring actual population infiltration of the damaged genetic material.

\section{TABLE 1: Requirements for successful use of the sterile insect technique.}

\begin{tabular}{|c|c|}
\hline Rearing & Mass rearing of high quality insects (using the correct quality measures). \\
\hline Sterility & Correct dose for optimised fitness and sterility. \\
\hline Spatial release & $\begin{array}{l}\text { Distribute sterile insects throughout the target area so they thoroughly } \\
\text { mix and mate with the wild population. }\end{array}$ \\
\hline Fitness & Releases compete successfully for mates in the environment. \\
\hline Timing & Releases must coincide with the full reproductive period of the target. \\
\hline SIT ratio & $\begin{array}{l}\text { Large enough numbers of SIT releases to overcome the natural rate of } \\
\text { increase of the population. }\end{array}$ \\
\hline $\begin{array}{l}\text { Closed } \\
\text { population }\end{array}$ & No immigration of fertile insects from outside the target zone. \\
\hline
\end{tabular}

Many population models have attempted to quantify the factors that influence population suppression under SIT (e.g. Knipling 1979). Parameters involved in the first test of SIT, conducted against screwworms by Knipling on the Caribbean island of Curacao in the mid-1950s, have been incorporated in software (ipmworld.umn.edu/ chapters/sirsimul.htm, accessed March 2003). This program permits the user to vary biological variables such as fitness, spatial variables (e.g. the number and location of release points) and operational parameters (e.g. the number of insects released).

\section{NEW ZEALAND'S FIRST SIT CASE STUDY}

Painted apple moth (Teia anortoides)(Lepidoptera: Lymantriidae) is an Australian species that is the target of an eradication programme operated by the Ministry of Agriculture and Forestry (Suckling et al. 2002). The effect of irradiation dose on sterility 
of this species was recently reported (Suckling et al. 2002). This initial study was necessary prior to release of sterilised males to assess likely moth dispersal and assist with the interpretation of trap catches as part of the monitoring programme. Sterility of released males was considered necessary to avoid adverse impacts on the eradication effort. The existence of an extensive trapping grid across Auckland meant that the additional costs of rearing, sterilising and releasing males were relatively minor. The extensive use of virgin females as lures in the trapping grid provided the advantage of a ready supply of males for sterilisation and release. Also, the efficiency of using both males and females in different parts of the eradication programme against this species offered a significant cost saving.

Males irradiated at 160 Gy were released and recaptured up to several kilometres from a single release site in an area with a persistent breeding population in Auckland between February and May 2002 (D.M. Suckling et al. unpubl. data). A total of ca 3500 males were released at Waikumete Cemetery on eight occasions. This pilot study developed the theoretical basis for a proposal to apply SIT in the following year.

In 2003, males irradiated as pupae at 100 Gy were released weekly from February to June at three sites with known or suspected painted apple moth breeding populations. By May 2003, 45,000 males had been released and recapture ratios averaged ca 100:1 of sterile to wild males. Laboratory studies found some effects on moth fitness (e.g. reduced rate of arrival to calling females in a wind tunnel), as well documenting the rate of accumulated mortality in the $\mathrm{F}_{1}$ and $\mathrm{F}_{2}$ progeny of irradiated male pupae. Irradiated males dispersed up to $10.5 \mathrm{~km}$ in the field (D.M. Suckling et al. unpubl. data). All indications from a preliminary analysis of the programme are positive, including a highly favourable cost:benefit analysis. Huge reliance was placed on previously published work on other lepidopteran species, for budgetary and logistic reasons, as well as on mass rearing of high quality insects.

\section{FUTURE POTENTIAL FOR THE USE OF SIT IN NEW ZEALAND}

Other possible targets for future use in New Zealand include all those exotic species for which excellent data sets and precedents exist (e.g. Queensland fruit fly), as well as those for which mass rearing, attractants and other requisites can be rapidly imported or developed (e.g. Lymantriidae). The challenge faced by New Zealand's biosecurity scientists is to provide anticipatory ready-response capabilities in the evaluation of the potential for eradication, underpinned by the specifics of tactics like SIT. The rapid development of a mass rearing system for new incursions is a logistical challenge that highlights a race between pest population expansion in the field and the laboratory, and underscores the need for rapid decision making after the discovery of an unwanted organism, in order to maximise the number of sterile insects released as early as possible.

\section{SIT and gypsy moth}

The issue of logistics is exemplified by the recent detection of a single Asian gypsy moth (Lymantria dispar) in a pheromone trap in Hamilton. The theoretical use of SIT needs to at least be considered as part of an eradication response to this incursion. A previous cost:benefit analysis favoured eradication of Asian gypsy moth at a cost of $\$ 11 \mathrm{M}$ (J. Mumford, unpubl. data). This amount was based on the cost of aerial spraying of white spotted tussock moth (Orgyia thyellina) for eradication from Auckland, New Zealand. It is possible that aerial spraying of Btk may present the "best" option for Asian gypsy moth, although opponents to such a programme will ask for alternative technologies to be examined. Possible alternatives available to New Zealand with previous use in USA include mating disruption, virus (Glare et al. 1998), and the sterile insect technique. While mating disruption is today the preferred option in USA (Sharov et al. 2002), SIT arguably has the fewest issues with the Hazardous Substances and New Organisms Act (1996). However, there are other considerations.

Despite the highly evolved case of SIT for the "slow-to-spread" programme of gypsy moth in USA, there are logistical constraints in NZ that would require rapid and effective 
responses to be overcome. A SIT programme in NZ against Asian gypsy moth (assuming a favourable cost:benefit analysis) would require:

- A feasibility analysis and a timely funding decision.

- $\quad$ Field discovery and collection of sufficient insects to establish a breeding population.

- $\quad$ Rapid development of a mass rearing method and facility on a scale broadly similar to painted apple moth (several thousand insects per week).

- $\quad$ Irradiation biology (mainly from published sources).

- $\quad$ Legislative (HSNO Act 1996) issues to be resolved rapidly.

- Logistical issues to be resolved rapidly.

\section{Legislative limitations}

The HSNO Act (1996) requires an application to be made to the Environmental Risk Management Authority for approval to release any organism not recognised as present in New Zealand as at July 1998. The release of any organism whatsoever in reserves also requires the approval of the Dept. of Conservation; permission was granted for the painted apple moth releases in Waikumete Cemetery. Future incursions would require approval before SIT could be used, and the timeline for this process should be fasttracked in the interests of economic efficiency. It is obviously far easier to eradicate small rather than large populations, but eradication is never easy and New Zealand needs to raise the probability of success or face the economic consequences of failure.

\section{Internal biosecurity or pest management using SIT}

There may also be an economic case to be made for SIT to be used in the management of certain pests (e.g. sheep blowfly). Future use of the tactic could support attempts to maintain areas of freedom from a pest or "internal biosecurity". A possible example of this would be preventing the establishment of Oriental fruit moth in the South Island. The general area of internal biosecurity is acknowledged to be logistically difficult, but it is suggested that a "slow to spread" approach (e.g. between the North and South Islands) could well stand up to economic analysis in selected cases.

\section{CONCLUSIONS}

New Zealand should neither underestimate the economic importance of biosecurity incursions, nor should it avoid rapid testing or development of the few approaches that are of low risk and have high potential benefit to contribute to pest eradication. Regulatory procedures could be streamlined to better enable biosecurity responses. There are no grounds for complacency in the area of biosecurity in New Zealand, and a greater focus on this area is warranted. This is especially true for the potential of the sterile insect technique, given several decades of success with SIT elsewhere.

\section{ACKNOWLEDGEMENTS}

Funding was provided by FRST and the Ministry of Agriculture and Forestry Biosecurity Authority. Dr David Baird (AgResearch) helped with the modelling of SIT for painted apple moth, which showed the potential benefit of this tactic in the eradication of this species. The author is a member of the Environmental Risk Management Authority but the views are those of the author alone. I am grateful to the following colleagues for constructive comments about SIT: Dr Steve Goldson, Dr David Baird, Graham Burnip and John Charles.

\section{REFERENCES}

Bartlett, A.C.; Staten, R.T. 2003: The Sterile Insect Release Method and Other Genetic Control Strategies. http://ipmworld.umn.edu/chapters/bartlett.htm (accessed 16/03/ 03)

Bloem, S.; Bloem, K.A.; Carpenter, J.E; Calkins, C.O. 2001: Season-long releases of partially sterile moths for control of codling moth, Cydia pomonella (L.), (Lepidoptera: Tortricidae) in Washington apples. Environ. Entomol. 30: 763-769. 
Calvitti, M.; Remotti, P.C.; Cirio, U. 2000: The sterile insect technique in the integrated pest management of whitefly species in greenhouses. In: Tan, K.H. ed. Area Wide Control Of Fruit Flies And Other Insect Pests. Joint Proceedings of The International Conference On Area Wide Control of Insect Pests. Penang, Malaysia. Pp.185-192.

Carpenter, J.E. 1991: Effect of radiation dose on the incidence of visible chromosomal aberrations on Helicoverpa zea (Lepidoptera: Noctuidae). Environ. Entomol. 20: 1457-1459.

Glare, T.R.; Barlow, N.D.; Walsh, P.J. 1998: Potential agents for eradication or control of gypsy moth in New Zealand. Proc. 51st N.Z. Plant Prot. Conf.: 224-229.

Goldson, S.L.; Sucking, D.M. (ed.) 2003: Defending New Zealand's Green Oasis: The Role of Science in Biosecurity. New Zealand Plant Protection Society, Christchurch.

Hendrichs, J. 2000: Use of the sterile insect technique against key insect pests. Sustainable Development International 2: 75-79.

Hendrichs, J.; Robinson, A. S.; Cayol, J. P.; Enkerlin, W. 2002: Medfly areawide sterile insect technique programmes for prevention, suppression or eradication: the importance of mating behavior studies. Florida Entomol. 85(1): 1-13.

IAEA 2000: Improvement of codling moth SIT to Facilitate Expansion of Field Application. Int. Atomic Energy Agency IAEA-D4-00CT08578, Vienna, Austria. $29 \mathrm{p}$.

Knipling, E.F. 1979: The basic principles of insect population suppression and management. U.S. Dep. Agric. Agric. Handbook No. 512. 659 p.

Krafsur, E.S. 1998: Sterile insect technique for suppressing and eradicating insect population: 55 years and counting. J. Agric. Entomol. 15(4): 303-317.

LaChance, L.E. 1985: Methods For The Control Of Lepidopteran Species: Status and Potential. US Dept. Agriculture, Agricultural Research Service ARS-28. 40 p.

Meats, A. 1996: Demographic analysis of sterile insect trials with the Queensland fruit fly Bactrocera tryoni (Froggatt) (Diptera: Tephritidae). Gen. Appl. Entomol. 27: 212.

Moriya, S.; Miyatake, T. 2001: Eradication programs of two sweetpotato pests, Cylas formicarius and Euscepes postfasciatus, in Japan with special reference to their dispersal ability. J. Agric. Res. Quarterly 35(4): 227-234.

O'Callagahan, M.; Glare, T.R.; Jackson, T.A. 2003: Biopesticides for control insect pestincursions in New Zealand. In: Goldson, S.L.; Sucking, D.M. ed. Defending New Zealand's Green Oasis: The Role of Science in Biosecurity. New Zealand Plant Protection Society, Christchurch. Pp. 137-152.

Robinson, A.S.; Franz, G. 2000: The application of transgenic insect technology in the sterile insect technique. In: Insect transgenesis: Methods and Applications. Handler, A.M.; James, A.A. ed. CRC Press, Boca Raton, USA. Pp. 307-318.

Sharov, A.A.; Leonard, D.; Liebhold, A.M.; Clemens, N.S. 2002: Evaluation of preventive treatments in low-density gypsy moth populations. J. Econ. Entomol. 95: 12051215.

Suckling, D.M.; Hackett, J.; Daly, J. 2002: Sterilisation of painted apple moth Teia anortoides (Lepidoptera: Lymantriidae) by irradiation. N.Z. Plant Prot. 55: 7-11.

Suckling, D.M. 2000: Managing urban weeds and pests: Context and considerations. In: Suckling, D.M.; Stevens, P.S. ed. Managing Urban Weeds and Pests. New Zealand Plant Protection Society, Christchurch. Pp. 3-8.

Tothová, A.; Marec, F. 2000: Chromosomal principle of radiation-induced $\mathrm{F}_{1}$ sterility in Ephestia kuehniella (Lepidoptera: Pyralidae). Genome 44: 172-184. 